\title{
Fuentes, género y sentido de El maestro de Alejandro de Antonio Enríquez Gómez, una comedia pseudohistórica
}

\author{
IVÁN Gómez CABAllero ${ }^{1}$ \\ Universidad de Castilla - La Mancha
}

Resumen: El presente trabajo se centra en El maestro de Alejandro, una comedia aurisecular del conquense Antonio Enríquez Gómez, y ahonda en varios aspectos, como las fuentes, el género y el sentido. Se explica, además, por qué El maestro de Alejandro no guarda relación con el resto de comedias del siglo XVII en las que Alejandro Magno es protagonista (Las grandezas de Alejandro de Lope de Vega, La mayor hazaña de Alejandro atribuida a Lope de Vega y Darlo todo y no dar nada de Calderón de la Barca), definiendo su pseudohistoricidad y su separación de la tradición literaria.

Palabras clave: Antonio Enríquez Gómez, Alejandro Magno, historia, Grecia, tradición.

Sources, genre and meaning of El maestro de Alejandro by Antonio Enríquez Gómez, a pseudohistorical comedy

Abstract: This work focuses on El maestro de Alejandro, a secular comedy by Antonio Enríquez Gómez, and it delves into various aspects, such as sources, genre and meaning. It also explains why El maestro de Alejandro is not related to the rest of the seventeenth-century's comedies in which Alexander the Great is the protagonist (Las grandezas de Alejandro by Lope de Vega, La mayor hazaña de Alejandro attributed to Lope de Vega and Darlo todo y no dar nada by Calderón de la Barca), defining its pseudohistoricity and its separation from the literary tradition.

Keywords: Antonio Enríquez Gómez, Alejandro Magno, history, Greece, tradition.

1 Este trabajo ha sido financiado gracias al Ministerio de Educación y Formación Profesional con una beca de colaboración en el Departamento de Filología Hispánica y Clásica de la Universidad de Castilla-La Mancha durante el curso 2019/2020 («Edición y estudio del teatro de Antonio Enríquez Gómez»), dirigida por el Dr. Rafael González Cañal, a quien agradezco su ayuda y sus sugerencias aportadas. 


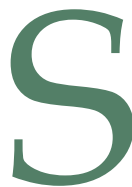
in Alejandro Magno no podríamos entender la Antigüedad clásica. Su vida siempre ha suscitado el interés de las artes desde la Antigua Grecia hasta la actualidad. Concretamente, el rey macedonio cautivó a los dramaturgos del siglo XvII: a Félix Lope de Vega y Carpio (1562-1635) con Las grandezas de Alejandro y La mayor hazaña de Alejandro Magno, de autoría dudosa; a Fernando de Zárate - pseudónimo de Antonio Enríquez Gómez (1600-1666) - con El maestro de Alejandro; a Pedro Calderón de la Barca (16001681) con Darlo todo y no dar nada y, por último, a José de Cañizares (1676-1750) con la mojiganga burlesca Alejandro Magno. La huella de la literatura grecolatina ha configurado, en buena medida, la occidental, de modo que el teatro del siglo XVII bebe de ella. Los objetivos de nuestro estudio se fundamentan en un análisis de El maestro de Alejandro, ahondado en las fuentes, el género dramático y el sentido. La estructura de nuestro trabajo es la siguiente: en $§ 1$ estudiamos el género de esta comedia, en $\S 2$ dirimimos las posibles fuentes y en $\S 3$ estudiamos el sentido completo de la obra, orientada a la crítica política y sustentada en las ideas políticas de Política angélica y Luis dado de Ana... de Antonio Enríquez Gómez. Por último, en $\S 4$ extraemos las principales cuestiones de nuestro estudio. A lo largo de este trabajo, se citarán versos de El maestro de Alejandro de Antonio Enríquez Gómez (2005), siguiendo la edición de Germán Viveros, y también de Las grandezas de Alejandro de Félix Lope de Vega Carpio (2017), citando versos de la edición de Anne Marie Lievens.

\section{Género}

El maestro de Alejandro debe encuadrarse como una comedia de ambientación clásica. De hecho, Enríquez Gómez escribió varias de ellas² ${ }^{2}$ por ejemplo, Amor con vista y cordura, sobre el romano Marco Aurelio; Los dos filósofos de Grecia, sobre Heráclito y Demócrito; La culpa más provechosa y vida y muerte de

\footnotetext{
2 Su corpus dramático está integrado por un total de 40 comedias, de las cuales 10 se han perdido, y se le atribuyen otras 10. La clasificación del teatro de Enríquez Gómez se puede dividir en comedias de capa y espada (A cada paso un peligro, Mayor mal hay en la vida...), comedias palatinas (A lo que obligan los celos, Engañar para reinar...), comedias históricas (A lo que obliga el honor, Los dos filósofos de Grecia, Las tres coronaciones del emperador Carlos V), comedias de valientes (El capitán Chinchilla, El valiente Campuzano), comedias hagiográficas y religiosas (El médico pintor san Lucas, La defensora de la reina de Hungría), comedias bíblicas (La prudente Abigail, La soberbia de Nembrot), entremeses, loas, comedias no conservadas y atribuidas, cuyas autorías se disputan entre Lope de Vega, Calderón de la Barca, Mira de Amescua, Agustín Collado del Hierro y Francisco de Villegas, entre otros. Las comedias de ambientación clásica están presentes tanto en capa y espada, palatinas e históricas. Así pues, el Instituto Almagro de teatro clásico, centro de I+D de la Universidad de Castilla - La Mancha, está editando las comedias de Antonio Enríquez Gómez (2015, 2018, 2019b).
} 
Poncio Pilato ${ }^{3}$, entre otras. Los temas clásicos son, junto a los religiosos ${ }^{4}$ y bíblicos $^{5}$, recurrentes en su obra teatral, poética y narrativa, donde las relaciones intertextuales son más que patentes. Enríquez Gómez elaboró una trama ficticia para esta comedia apoyándose en tres figuras históricas: el príncipe Alejandro de Macedonia, el filósofo Aristóteles y el rey Filipo de Macedonia. $\mathrm{El}$ argumento no se basa en la historiografía grecolatina ${ }^{6}$, ni tampoco guarda relación con otras comedias áureas que versan sobre Alejandro Magno -Las grandezas de Alejandro, La mayor hazaña de Alejandro y Darlo todo y no dar nada-. Los anacronismos son variados y destacables: lugares y referencias a España como Guadix y Girona, y también a fortificaciones medievales, como el castillo ${ }^{7}$ en que Octavia es encerrada; además, en las acotaciones se citan instrumentos del siglo XVII, por ejemplo, las chirimías y los atabalillos. Algo que nos sorprende es que el dramatis personae no es verosímil respecto a la tradición, ya que la onomástica es latina, y no griega, y los títulos nobiliarios son, en ocasiones, inverosímiles.

Esta comedia, más que como histórica, la hemos de clasificar como «pseudohistórica», puesto que incorpora personajes históricos dentro de una trama ficticia plagada de incoherencias. No nos hemos de sorprender de ello, pues la mayoría de las comedias - en principio, históricas - de Enríquez Gómez, son, en realidad, pseudohistóricas. Por ejemplo, a esta categoría debemos añadir A lo que obliga el honor, drama ficticio de honor conyugal basado en personajes históricos como Pedro I el Cruel, María de Padilla y Enrique de Saldaña, junto a Amor con vista y cordura ${ }^{8}$, cuya trama es totalmente artificial y absurda, en la

3 Según Hurzáiz Tortajada (2002: 300), La culpa más provechosa y vida y muerte de Pilatos es una refundición de El dichoso desdichado, Poncio Pilato de Espinosa Malagón. La comedia plantea problemas de autoría, ya que hay varios manuscritos que señalan que su autoría no es de Enríquez Gómez, sino de Francisco de Villegas, autor aurisecular del que actualmente se sabe muy poco.

4 Vid. La conversión de santa María Madgalena, La defensora de la reina de Hungría, Mártir y rey de Sevilla, san Hermenegildo, El médico pintor san Lucas, Las misas de san Vicente, El obispo de Crobia, san Estanislao, San Antonio Abad, Santa Pelagia y, por último, El vaso y la piedra. Estas obras todavía no se han editado críticamente, al igual que las de la nota 4.

5 Vid. La escala de la gracia, La prudente Abigaíl y La soberbia de Nembrot.

6 Me refiero a Calístenes de Olinto, Anaxímenes de Lampsaco, Ptolomeo I, Aristóbulo de Casandrea, Onesícrito, Nearco, Clitarco de Alejandría, Diodoro, Quinto Curcio Rufo, Justino, Plutarco de Queronea, Pseudocalístenes, entre otros. Vid. Gómez Espelosín (2001) para explicación más amplia sobre las fuentes clásicas de Alejandro Magno.

7 Vid. Gutiérrez Gil (2019) para la simbología del castillo en el teatro de Francisco de Rojas Zorrilla, muy similar a la simbología en Antonio Enríquez Gómez.

8 Ha sido recientemente publicada por el Instituto Almagro de teatro clásico en el tomo I de Academias morales de las Musas editada por Almudena García González (2015). 
que aparece Marco Aurelio. Asimismo, Julio Giménez (2018) ha rastreado los anacronismos y el argumento de otra comedia pseudohistórica: No hay contra el honor poder. Por otra parte, en el prólogo introductorio de A lo que obliga el honor, González Cañal (2015: 134) señaló que existen muchas comedias pseudohistóricas en el Siglo de Oro, y no solamente de Enríquez Gómez, como, por ejemplo, Los comendadores de Córdoba de Lope de Vega, Del rey abajo, ninguno, atribuida a Rojas Zorrilla, La mayor venganza de honor de Álvaro Cubillo de Aragón y También la afrenta es veneno, comedia en colaboración de Luis Vélez de Guevara, Antonio Coello y Francisco de Rojas. En la clasificación del teatro de Enríquez Gómez, El maestro de Alejandro se encuentra en las comedias historiales, pero considero que no responde exactamente a las características de dicho género, puesto que comparte rasgos con las palatinas.

Podemos, por tanto, analizarla desde el prisma del hibridismo genérico; de hecho, García González (2015) duda también sobre la adscripción de Amor con vista y cordura, otra comedia pseudohistórica similar a El maestro de Alejandro con una trama ficticia y con personajes históricos. Ya Bances Candamo (1970: 33) realizó en el siglo XVII una definición genérica, diferenciando, por un lado, las comedias historiales, que siguen la tradición, y, por otro, las amatorias, que son "pura invención o idea sin fundamento en la verdad». Siguiendo esta distinción de Bances Candamo, El maestro de Alejandro sería una comedia de fábrica9 ${ }^{9}$. Por otra parte, Florit (2000: 65 - 83), citado por Zugasti (2003: 161 - 162), pretendió clasificar el teatro de Tirso de Molina y aportó algunas características de las comedias palatinas ${ }^{10}$ :

- Presencia de un personaje histórico en la comedia.

- El amor es el motor principal de la acción.

- Hay una simbiosis social entre los personajes, que son, por un lado, nobles y, por otro, de menor capa social, como criados y gracioso.

- Es destacable también que una dama se enamora de un subordinado y le declara su amor mediante lenguaje no verbal, cartas y oraciones ambiguas.

9 Siguiendo el Diccionario de Autoridades, «fábrica» vendría a equipararse con ficcionalidad.

10 Resultan, además, imprescindibles los estudios de Arata (1998), Oleza (1997), Parker (1976), Serralta (1988), Wardropper (1978) y Weber de Kurlat (1975, 1976, 1977). 
El maestro de Alejandro sigue perfectamente las características de Florit (2000: 65 - 83). Así pues, Zugasti (2003: 159 - 185), con el objetivo de definir aún más la comedia palatina de los Siglos de Oro, aportó algunas características, que nos van a servir de base para encuadrar el género de nuestra comedia:

- La acción se sitúa en una temporalidad total o, por el contrario, en una época lejana: El maestro de Alejandro cumple este rasgo, ya que se ambienta en la Grecia alejandrina, aunque, en ocasiones, la deixis espacial alude a castillos, propios de la Edad Media, y no de la Edad Antigua.

- Como sostiene Zugasti (2003: 163 - 164), «los personajes se mueven en lugares (espacio dramático) cuya marca principal consiste en estar fuera de Castilla». De nuevo, esta comedia satisface esa característica al estar ambientada en Grecia.

- Se abordan «episodios (no siempre airosos) acaecidos a reyes, duques u otros altos personajes» (Zugasti, 2003: 164). En El maestro de Alejandro existe, efectivamente, un conflicto amoroso entre Alejandro, príncipe de Macedonia; Octavia, Camilo, que es infante de Sidón, y Julia, princesa de Egipto.

- «Otra característica del género palatino es que sus protagonistas pertenecen, de un lado, a la realeza o a la más alta nobleza (reyes, príncipes, duques, marqueses, condes ...) y, de otro, a las gentes subalternas con las que traban contacto diario (pastores, jardineros, criados, secretarios, damas de compañía). Debido a esta doble extracción de los personajes, a menudo la acción (y la tensión) gira alrededor del problema de la desigualdad social o estamental de unos y otros» (Zugasti, 2003: 164). Aunque todos los personajes son de alta alcurnia, y no encontramos capas bajas de la sociedad, más allá de los criados y graciosos, es cierto que el rey Filipo no quiere casar a su hijo Alejandro con Octavia por ser de nobleza inferior y prefiere casarla con Julia, princesa de Egipto, para que, después de su muerte, el Estado griego siga siendo fuerte. A partir de este punto, se desarrolla una trama en la que Alejandro se rebela contra su padre y la razón de Estado.

- La acción se desarrolla en el palacio macedonio del rey Filipo y sus alrededores, rasgo fundamental de la comedia palatina. 
- La onomástica, como afirma Zugasti (2003: 165), posee «ribetes altisonantes que se salen de lo cotidiano». Sin embargo, estos personajes no son castellanos y, por tanto, se aleja en parte de otras comedias típicamente palatinas, como El guante de doña Blanca de Lope de Vega, Quien calla otorga, La fingida Arcadia y Amor y celos hacen discretos de Tirso de Molina, y Nadie fie su secreto de Calderón de la Barca.

- El maestro de Alejandro se aleja de la comedia palatina típica en que no hay ocultamientos ni disfraces, recursos de los que se sirven los dramaturgos para enredar la trama.

- Pero sí se cumplen subtemas relacionados con la política, el poder, el honor y la amistad: se cuestiona la razón de Estado y Alejandro duda de que Aristóteles actúe correctamente, ya que, más que actuar por la razón, lo hace por la autoridad regia.

\section{Fuentes}

En el apartado anterior sostenía que El maestro de Alejandro es una obra pseudohistórica porque no se sustenta en la tradición literaria grecolatina, ni tampoco en las comedias áureas del Siglo de Oro de Lope de Vega ni de Calderón de la Barca que incorporan el personaje de Alejandro. Los personajes de esta comedia guardan, salvando las distancias, relaciones onomásticas con los de otra comedia de Enríquez Gómez: Celos no ofenden al sol. Los personajes de ambas pueden entenderse como un fractal: en dicha comedia encontramos a un personaje llamado Alejandro, que también se siente angustiado; Julio, criado y gracioso de Celos..., se puede vincular con la princesa Julia de El maestro de Alejandro; Camila, criada de Rosaura, con el infante Camilo, y, por último, Octavio, consejo del rey Eduardo, con Octavia, enamorada de Alejandro. Podemos hablar, pues, de un autoplagio onomástico, con el que Antonio Enríquez Gómez siente predilección por determinados nombres. Asimismo, es curioso que los personajes de $E l$ maestro de Alejandro aparezcan en estructuras duales: Alejandro y Octavia, el rey Filipo y Aristóteles, Julia y Camilo y, por último, Tabaco y Elena.

Si comparamos, por ejemplo, los personajes de Las grandezas de Alejandro de Lope de Vega, que sigue fielmente la tradición ${ }^{11}$, con los de El maestro de

11 Vid. Lida de Malkiel $(1957)$, Lievens $(2017,2020)$ y Pejenaute $(1985,1991)$ para una explicación más detallada sobre las fuentes de Las grandezas de Alejandro. 
Alejandro, nos damos cuenta de esta pseudohistoricidad. En El maestro de Alejandro, Alejandro Magno es el protagonista de la obra y es presentado como hijo del rey Filipo y discípulo de Aristóteles: nada se nos dice sobre quién es su madre ${ }^{12}$. Hasta este punto, las relaciones históricas son adecuadas, pero después se convierte en un personaje inverosímil. Se presenta como hijo de Marte: en primer lugar, es un anacronismo porque Enríquez usa dioses latinos, y no griegos, y, en segundo lugar, viola la tradición historiográfica porque era hijo de Zeus Amón ${ }^{13}$, o, en su caso, de Júpiter Amón:

Aunque fue mi inclinación, por hijo de Marte, siempre (vv. 80 - 81).

Alejandro es ambicioso y quiere ampliar su reino; para ello, su padre Filipo decide casarlo con Julia, princesa de Egipto, pero él se niega, pues ama a Octavia. Tampoco es real el conflicto y el enredo amoroso entre Alejandro y Octavia, ni que batallara cuando el rey Filipo estaba vivo, pues heredó el trono cuando él murió y, a partir de ese momento, inició las grandes expediciones militares para conseguir la hegemonía de Macedonia. Se muestra, pues, como un personaje rebelde que no acata las decisiones reales: lucha por casarse con Octavia, aunque su padre no quiera. En cierto sentido, el Alejandro de Las grandezas de Alejandro de Lope se asemeja al de Enríquez Gómez en que es un monarca poderoso al que sus súbditos adoran por su valentía, su coraje y su gran decisión; posee, asimismo, un carácter incasable por querer llevar a Macedonia a la cima del mundo. Hay, pues, una cierta relación entre el origen divino de ambos: Lope lo considera «hijo divino de Júpiter ${ }^{14}$ y Marte» (vv. 654-655), mientras que Enríquez, «hijo de Marte» (vv. 80 - 81). Por tanto, Enríquez Gómez comete una incongruencia histórica, ya que ningún autor - ni español, ni griego, ni latino - había señalado que Alejandro es hijo de Marte únicamente. El papel que juegan los dos Alejandros en la acción es muy diferente: por un lado, a Lope de Vega le interesa el conflicto bélico, mientras que Enríquez prefiere decantarse por el amoroso, inventándose una trama totalmente ficcional.

12 En Las grandezas de Alejandro (Lope de Vega, 2017), aparece Olimpíade, madre de Alejandro, que le comunica su origen divino para engrandecer sus hazañas guerreras.

13 Epíteto mitológico con el que era conocido a Zeus en Egipto y con el que se le equiparaba al dios egipcio Amón.

14 Sigue la tradición historiográfica de Vida y hazañas de Alejandro Magno de Pseudocalístenes, novela que, al igual que El maestro de Alejandro, ficcionaliza muchos datos sobre el macedonio. Cabe destacar que su influencia en la tradición literaria se debe fundamentalmente a la conexión de Alejandro con Zeus Amón. 
En El maestro de Alejandro, Octavia, duquesa de Utelino ${ }^{15}$, quiere a Alejandro Magno, pero acata tristemente la razón de Estado, aunque en ciertos diálogos muestra su hipocresía: lo ama, pero obedece a su padre, el rey Filipo y, posteriormente, se queja de sus decisiones. El nombre, por ejemplo, no es griego, sino latino ${ }^{16}$, desvinculándose, por tanto, de la tradición literaria. En cambio, Julia está caracterizada como princesa de Egipto e hija de Julio Tiro; también galantea a Alejandro, pero no soporta que él no lo haga, por lo que decide no casarse con él. Esta princesa nunca existió durante la vida de Alejandro, ya que Egipto fue gobernada por Darío III, su feroz enemigo, cuyas hijas eran Barsine-Estatira y Dripetis, y, tras la muerte de Darío, administrada por su general, el diádoco Ptolomeo I Sóter ${ }^{17}$ (367 - 285 a. C.), que solamente tuvo una hija, Arsínoe II (316 - 270 a. C.), reina de Tracia y, posteriormente, corregente de Egipto. De nuevo, subrayamos la pseudohistoricidad de la obra. Julia es, por tanto, un producto ficcional de Enríquez Gómez. Por otra parte, Camilo es el infante de $\operatorname{Sidón}^{18}$ y, en cierto modo y salvando las distancias, se puede relacionar con Dolomino, personaje histórico que aparece en Las grandezas de Alejandro de Lope, que fue rey de Sidón. En un primer momento, estaba destinado a casarse con Octavia - Alejandro lo odia por ello - y finalmente se casa con la princesa Julia. Solamente aparece en momentos tensos y conflictivos de la obra para discutir y luchar con Alejandro por Octavia.

Es cierto que en las comedias del siglo XVII sobre Alejandro Magno también está patente el enredo amoroso, pero de forma muy diferente. En La mayor hazaña de Alejandro, atribuida a Lope de Vega, y Darlo todo y no dar nada de Calderón de la Barca, hay un mismo conflicto amoroso ${ }^{19}$ basado en la historiografía griega, y también en las polianteas renacentistas, entre Alejandro Magno, su pintor Apeles y Campaspe. Por otra parte, tal conflicto no está en Enríquez Gó-

\footnotetext{
15 No he logrado averiguar la localización exacta de esta región, por lo que cabe pensar que es también inventada por Antonio Enríquez Gómez.

16 Los romanos llamaban Octavia u Octavio a los hijos e hijas que nacían en octavo lugar.

17 Tras la llega de Alejandro, el griego Ptolomeo se apodera de Egipto y se inicia el periodo helenístico del Antiguo Egipto (332 - 30 a. C.), que finaliza con la batalla de Actium, cuando Cleopatra y Marco Antonio mueren y Octavio entra en Alejandría.

18 Sidón es la tercera mayor ciudad del Líbano y se encuentra a 40 kilómetros de Tiro. Es una de las ciudades más antiguas del mundo puesto que se fundó alrededor del tercer milenio antes de Jesucristo.

19 Este trío amoroso está presente en Historia natural de Plinio (2002), Officina de Ravisio Textor (1699), traducida por Juan de la Cueva de Caroza, cuya edición se ha perdido; General estoria de Alfonso X el Sabio (2009), Silva de varia lección de Pedro Mejía (2003), Monarquía eclesiástica de Pérez de Pineda (1588), La mayor hazaña de Alejandro de Lope de Vega (s.a.) y Darlo todo y no dar nada de Calderón de la Barca (2019), entre otros. Sin embargo, Antonio Enríquez Gómez obvia este conflicto amoroso.
} 
mez, que ficcionaliza la historia con elementos propios, aunque es cierto que La mayor hazaña de Alejandro y Darlo todo y no dar nada pudieron servir de base.

Por otra parte, la educación del príncipe obtuvo gran importancia en el teatro áureo, fundamentalmente en la comedia palatina, y, como veremos, Enríquez Gómez estaba muy preocupado por temas políticos, tanto en su obra teatral, como en prosa. Por ejemplo, en Luis dado de Dios, considera que el poder regio ha de basarse en la justicia, prudencia y amor. González Cañal (2017) ha estudiado la figura del rey en el contexto dramático de Enríquez Gómez y Filipo de Macedonia, padre de Alejandro, se corresponde perfectamente con el rey prototípico de sus obras: un rey tirano al que no le importan los sentimientos de su familia, sino la razón de Estado. Filipo es un personaje histórico, pero en El maestro de Alejandro no está correctamente definido, puesto que se obvian y se falsean datos. Sin embargo, sí lo está en Las grandezas de Alejandro, comedia en la que se relata su asesinato por Pausanias de Orestis. Cabe pensar, pues, que a Enríquez Gómez solamente le interesa su figura onomástica, más allá de su configuración historiográfica. En cambio, Aristóteles es el valido, que, a su vez, constituye una figura destacable dentro de la producción teatral de Enríquez y, como apunta Calderón Calderón (2017: 108), da nombre por perífrasis a sus comedias políticas: Aristóteles, a El maestro de Alejandro; Gil de Albornoz, a El gran Cardenal de España don Gil de Albornoz, de la que existen dos partes; Heráclito y Demócrito, a Los dos filósofos de Grecia y Méndez Pinto, a Fernán Méndez Pinto ${ }^{20}$. Aristóteles es, pues, una figura clave en la obra, puesto que quiere manejar y conducir las conciencias de Octavia y Alejandro para que no se casen y que Alejandro lo haga con Julia, cumpliendo así la razón de Estado.

Así pues, habiendo señalado esas características, tenemos que excluir la posibilidad de que tanto Lope como Calderón sean la fuente de El maestro de Alejandro. En cambio, Amar por razón de Estado de Tirso de Molina parece ser fuente probable de El maestro de Alejandro por varios motivos en los que he encontrado semejanzas: Enríquez Gómez la tendría que conocer porque la cita en el verso 116 de la Academia II; ambas obras se desarrollan en un ambiente palaciego y nobiliario cuyos personajes están atados a la razón de Estado; el protagonista, bien Alejandro, bien Enrique, han sido educados en las precep-

20 Todavía no hay un estudio concluyente que aporte datos suficientes sobre la paternidad de esta comedia, atribuida también a Lope de Vega. 
tivas aristotélicas basadas en la ciencia y en la razón y no logran entender la razón de Estado, por lo que ambos se rebelan ante la imposibilidad de establecer una relación sentimental que contravenga las normas sociales y morales de las clases nobiliarias; el papel escrito juega un papel importante en ambas porque es un elemento de enredo dramático, propio de la comedia palatina; $y$, por último, el sintagma nominal «razón de estado» ${ }^{21}$ se repite en ambas obras. Según Sáez Raposo (2019: 55), fue muy utilizado a partir de Diez libros de la razón de Estado (1593) de Giovanni Botero, traducido por Antonio de Herrera y Tordesillas. Amar por razón de Estado se publicó en la Parte I de Tirso de Molina (Sevilla, Francisco de Lyra, 1627), casi cuarenta años antes que El maestro de Alejandro (1666). Enríquez Gómez pudo probablemente haber leído ${ }^{22}$ o conocido la obra y elaborar una comedia palatina cuyos temas centrales fueran la razón de Estado y el enredo amoroso. De lo que podemos estar completamente seguros es que no podemos vincular esta comedia directamente con las comedias españolas auriseculares en las que aparece Alejandro Magno (Las grandezas de Alejandro de Lope de Vega, La mayor hazaña de Alejandro atribuida a Lope y Darlo todo o no dar nada de Calderón de la Barca), puesto que Enríquez Gómez no tiene en cuenta la caracterización historiográfica del macedonio. Por tanto, considero que éstas no pueden ser las fuentes de nuestra comedia. La mayor hazaña... y Darlo todo... se pueden comparar, salvando las distancias, con El maestro de Alejandro en un solo motivo: el amoroso. No obstante, tanto Lope como Calderón, desarrollan un argumento basado en el conflicto amoroso de Campaspe, Alejandro y Apeles, frente a Enríquez Gómez, que elabora una trama ficticia basada en el de Julia, Camilo, Alejandro y Octavia, que no existe en la literatura medieval, renacentista ni barroca.

\section{Sentido}

Las acciones por las que los políticos mantienen la estructura fuerte del Estado para legitimar el poder constituyen la razón de Estado, que es un tema

21 En Amar por razón de Estado (Tirso de Molina, 2019), se cita 10 veces: «por solo razón de Estado» (v. 931, v. 1520), «razón de Estado es razón» (v. 946) «su ciega razón de Estado» (v. 2505), «razón de Estado se ha visto» (v. 2508), «ama por razón de Estado» (v. 2641), «amar por razón de Estado» (v. 2684), «iOh, amar por razón de Estado» (v. 3090), «que en esta razón de Estado» (v. 3114), « i [...] amáis por razón de Estado?» (v. 3131), y dos veces en El maestro de Alejandro: «por razón de Estado améis» (v. 1506) y «la razón de Estado injusta» (v. 2553).

22 No conocemos todavía a qué libros pudo Enríquez Gómez tener acceso a lo largo de su vida. 
muy recurrente de los tratadistas de los siglos XVI y XVII. Por tanto, la razón de Estado se opone a las razones personales, a las pasiones, a los sentimientos y a los intereses particulares, que quedan sepultados bajo los intereses del reino. En el siglo XVII mantener una relación amorosa secreta, como Enrique con Leonor en Amor por razón de Estado de Tirso de Molina y Alejandro con Octavia en El maestro de Alejandro de Antonio Enríquez Gómez, era un deshonor, tanto para la pareja, como para sus propias familias. Hasta el momento, el sentido de El maestro de Alejandro no ha sido estudiado, pero pienso que, a partir de sus argumentos políticos vertidos en Política angélica ${ }^{23}$ y Luis dado de Dios..., podemos analizarlo. Enríquez Gómez fue un hombre muy adelantado a su tiempo - de hecho, su pensamiento es más propio de la Ilustración que del Barroco -, pues aboga por la libertad, critica las injusticias, defiende la meritocracia, la importancia del comercio y la adecuación al puesto de ministro, así como también los excesivos gastos del Estado y los elevados impuestos. La mayoría de las obras de Enríquez Gómez pueden verse como una reivindicación de sus ideas políticas por los conflictos que presentan.

Calderón Calderón (2017) ha estudiado varias comedias cuyos contenidos versan sobre problemas políticos - entre las que incluye a El maestro de Alejandro -, como, por ejemplo, la dicotomía entre ley y poder, la razón de Estado y otros temas gubernamentales. Son frecuentes personajes que encarnan la autoridad regia absoluta ${ }^{24}$, detestados y criticados por Enríquez Gómez. Conectado con lo expuesto anteriormente, son habituales los conflictos entre los intereses del Estado y del individuo en sus comedias. Enríquez Gómez defiende siempre al individuo frente al Estado tiránico y absolutista ${ }^{25}$. Particularmente, El maestro de Alejandro desarrolla un conflicto por el que el bien del reino sepulta los sentimientos de los personajes y con el que se realiza una crítica implícita de esta situación, ya que las relaciones amorosas entre la nobleza del siglo Xvi se basaban en la razón de Estado. Estos argumentos apoyan la hipótesis de que Amar por razón de Estado de Tirso de Molina sea la fuente, puesto que el planteamiento y los conflictos entre ambas comedias son similares. En la tercera jornada, Alejandro, por ejemplo, se queja de la injusta razón de Estado, en un momento en que, tanto su padre Filipo, como

\footnotetext{
23 Fue incluida en el Índice de libros prohibidos de la Inquisición española. Destacamos también que ha sido editada críticamente hace unos pocos meses por Felice Gambin. Vid. Enríquez Gómez (2019).

24 Vid. González Cañal (2017) que estudia la figura del rey en las comedias de Enríquez Gómez.

25 Estas ideas pueden verse, como señalo, en Política angélica y Luis dado de Dios...
} 
su maestro Aristóteles, le han hecho creer que Octavia ha muerto, a pesar de estar viva y encerrada en un castillo, para que se olvide de ella:

La razón de estado injusta

me quitó a mi amada esposa,

porque casase con Julia.

Tirana ley, este lazo,

esta amorosa coyunda

rompió, a pesar de los dioses,

que las voluntades juntan. (vv. 2252 - 2559).

Y también se queja de Aristóteles, que aparece retratado como un consejero cruel al servicio del Estado ${ }^{26}$ :

El consejo fue cruel -de Aristóteles - sin duda;

Política que fue siempre

Mina, que voraz anual,

Con el fuego del estado,

La ignorancia más segura (vv. 2564 - 2569).

Inesperadamente, Aristóteles se pone del lado de Alejandro, pero ha de cumplir con la razón de Estado y ha de convencer al rey Filipo para que Alejandro pueda casarse con su amada Octavia y no con Julia:

Señor, vuestro padre viene,

luego hablaremos despacio

porque tan grave materia

pide consejo muy sabio.

Yo lo dispondré de modo

(asegurando el estado

y cumpliendo con las leyes

de maestro y vasallo)

que logréis vuestro deseo (vv. 2954 - 2962).

Anteriormente, ya en la primera jornada, Octavia había comunicado a Alejandro que su padre Filipo la había avisado de que este matrimonio no podía sustentarse, no por principios amorosos, sino por nobiliarios y por la razón

26 Vid. Calderón Calderón (2017) y González Cañal (2015) para un panorama más amplio de los personajes de validos y reyes en el teatro de Enríquez Gómez. 
de Estado. Además, Filipo le pide que no se preocupe, ya que, si no se casa con Alejandro, le encontrará un marido mejor:

Duquesa, este horrible amago

de la muerte que habéis visto,

es de mi justicia un rasgo

y de vuestra ruina aviso.

La princesa Julia, esposa

es del príncipe, mi hijo,

vos estorbáis estas bodas,

contra el mandamiento mío.

El amor que le tenéis

es conocido delirio

el que os tiene, vanidad

de su juventud y vicio.

Tomad estado, duquesa,

a vuestra sangre debido;

yo os daré esposo tan noble,

que iguale al blasón antiguo

de vuestra casa; Alejandro

de Julia ha de ser marido. (vv. 558 - 571).

El rey Filipo se muestra inflexible, pues cree firmemente que Octavia ha de casarse con Camilo, infante de Sidón e hijo del rey de Tiro, y no con su hijo Alejandro:

Princesa, ya he prevenido, para este daño presente

el remedio conveniente; ya Octavia tiene marido.

El infante de Sidón

(Camilo, del rey de Tiro

hijo, cuyo ingenio admiro

por su rara discreción),

esposo será de Octavia (vv. 848 - 856).

Y así se lo comunica a Camilo, infante de Sidón e hijo del rey de Tiro:

Camilo, obligado estoy

a los muchos beneficios 
que de Tiro y de Sidón

he recibido, y pretendo

(por debida obligación)

casaros hoy de mi mano.

La duquesa de Octavia es hoy

de la duquesa de Utelino

(sangre mía), nuevo sol;

ésta merece, Camilo,

por su rara discreción,

por su hermosura y por ser

de Macedonia blasón

ser vuestra esposa (vv. 889 - 902).

Más adelante, también le comunica a Octavia su deseo de que se case con el infante de Sidón:

El infante de Sidón

por esposo peregrino

os ofrece mi grandeza:

estimad mi ventura (vv. 936 - 939).

También el gracioso Tabaco sabe de la existencia de la razón de Estado, aquí se lo comunica al príncipe Alejandro de forma inocente:

Díjome: dile a Alejandro

que el rey su padre ha dispuesto

darle a la princesa Julia

por esposa, que el decreto

bajó ahora, según dicen,

del solio de su consejo. (vv. 174 - 178).

Pero Alejandro, contrario a la razón de Estado, ama a Octavia y rechaza esta injusta ley:

El rey no ha de permitir,

con cesáreo señorío

violentar el gusto mío,

dedicado a tu belleza,

que la suprema grandeza

no se opone al albedrío (vv. 676 - 681). 
Sin embargo, Octavia, temerosa por no seguir la ley ni la autoridad regia, le advierte a Alejandro de las posibles consecuencias, aunque sea contraria al amor que sienten ellos:

Casaos con Julia, señor,

pues así lo quiere el rey,

tenga la razón de su esfera,

la majestad su dosel

su pundonor la corona,

su cumplimiento la ley,

el estado su lugar,

y su decoro el laurel;

muera yo infeliz (vv. 690 - 698).

Por otra parte, Alejandro, alter ego de Antonio Enríquez Gómez en la obra, se opone firmemente a la potestad de su padre, el rey Filipo:

Yo soy su amante

y no he de dar al infante

lo que quiero para mí. [...]

Que la duquesa

de Utelino generosa,

si vos, gustáis es mi esposa (vv. 1365 - 1370).

Y su padre interpone las grandezas del reino macedonio, frente al amor que siente Alejandro por Octavia:

¿Vos queréis por la duquesa

perder un reino triunfante? (vv. 1376 - 1377).

El filósofo Aristóteles es usado como argumento de autoridad y una marioneta por parte de Filipo para que esta boda no se celebre:

Alejandro, aunque pudiera vuestra altivez disgustarme, repaso que sois mi hijo; y así, con amor de padre, procuro vuestros aumentos. Aristóteles, que sabe la naturaleza vuestra, 
me aconseja que os ampare;

y que si fuere posible,

que con la duquesa os case (vv. 1484 - 1494).

El príncipe Alejandro llega incluso a perder la razón, defendiendo su boda con Octavia y afirmando que no le importaría luchar y defenderla de su padre Filipo y del infante Camilo, llegando a morir por ella:

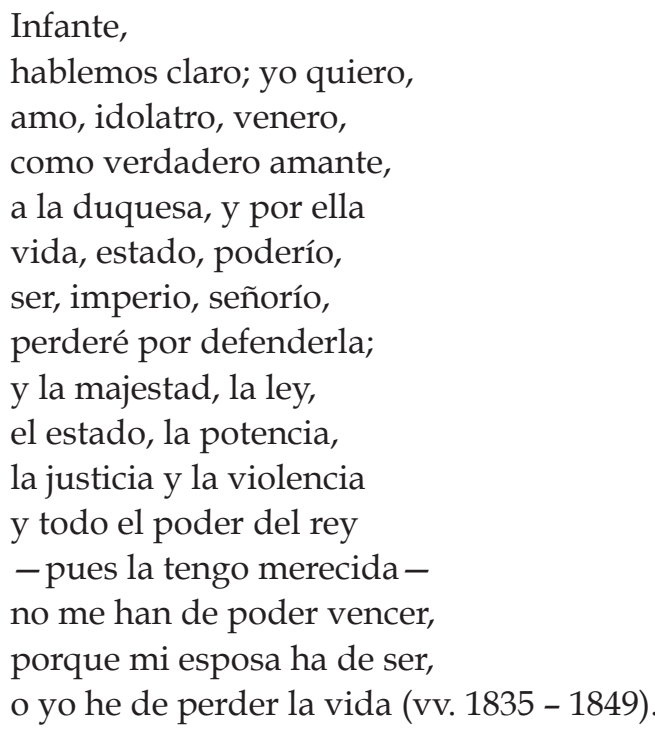

En la última jornada, Alejandro se va a luchar con el Imperio persa, mientras su padre Filipo encierra a la princesa Octavia para que él crea que ha muerto:

Triunfó al persa Alejandro, según lo dice esta carta, y con el triunfo el imperio en mayor peligro se halla.

Por no quererse casar con Camilo, puse a Octavia en prisión, y aunque se pierda Grecia, del orbe envidiada, ha de casar Alejandro con la princesa (vv. 2166 - 2174). 


\begin{abstract}
Aristóteles, cerremos
la puerta a la confianza, quede en los dos el secreto, corra luego la palabra de que la duquesa ha muerto; en la prisión muera Octavia, porque pie da la esperanza,
\end{abstract} Alejandro, de este amor (vv. 2180 - 2187).

Afortunadamente, Octavia consigue escapar del castillo, símbolo del poder regio y del asfixio moral del ser humano:

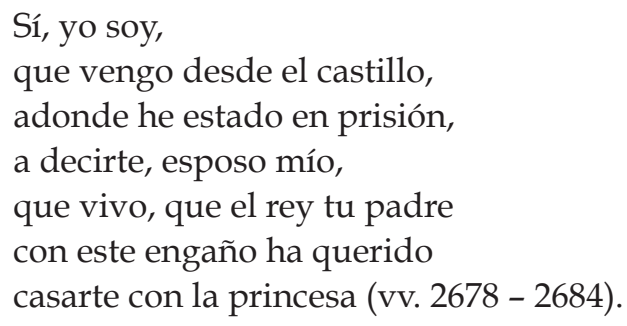

Alejandro le reprocha, pues, la actitud a Aristóteles, valido y filósofo del rey, por haberlo engañado con la muerte de Octavia, y el filósofo afirma que:

Yo nunca puedo servir mal, si me ajusto a la ley; porque quien sirve a su rey, es lealtad hasta morir; de mi la obediencia aprende a servir al superior (vv. 2826 - 2831).

Yo sólo sirvo a mi rey (v. 2841).

Ante la disculpa del filósofo, el príncipe macedonio, más allá de recriminar su actitud de nuevo, lo hace con su padre, mientras que a Aristóteles le dice que los vasallos no tienen voluntad ni libertad, ya que deben obedecer ciegamente a su rey:

La nueva que me trajisteis cuando yo llegué a palacio, de haber muerto la duquesa, 
no es cierta, porque fue engaño

de mi padre, presumiendo,

con este pretexto falso,

que yo casase con Julia;

en todo no he de culparos,

que las órdenes del rey

obedecen los vasallos (vv. 2920 - 2929).

El final no puede ser más calderoniano, ya que triunfa la felicidad sobre la desdicha y el amor sobre la razón de estado con el recurso de deus ex machina de Octavia:

\section{Deteneos.}

Sacro emperador Filipo,

príncipes de Grecia excelsos,

Octavia soy, que he bajado

de los palacios etéreos,

por mandado de los dioses,

a darle la mano luego

de esposa al príncipe (vv. 3162 - 3169).

En suma, en El maestro de Alejandro tenemos comportamientos diversos respecto a la razón de Estado: por un lado, al rey Filipo y a su marioneta, el filósofo y valido Aristóteles, que creen en un imperio fuerte basado en la razón de Estado, apoyados, a su vez, por el infante Camilo, y, por otro, el príncipe Alejandro y su amada Octavia, que creen que los sentimientos priman por encima de los asuntos regios. Sin embargo, la actitud de Alejandro es más firme que la de Octavia, ya que él desea oponerse a su padre desde el principio, mientras que Octavia duda en muchas ocasiones y, en determinados momentos de confusión, se suma a los deseos del rey Filipo.

\section{Conclusión}

Como señalamos en $\S 1$, dentro del cajón de sastre de las comedias historiales, hay multitud de subclasificaciones. El maestro de Alejandro es, por tanto, una comedia palatina con cierto hibridismo genérico de la comedia historial por recuperar la figura de Alejandro Magno, el rey Filipo y el filósofo Aristóteles, aunque, como señala Zugasti (2003), es un rasgo propio de la comedia 
palatina. En $\S 2$, subrayamos que la tradición literaria de la comedia áurea que recupera a Alejandro - Las grandezas de Alejandro, La mayor hazaña de Alejandro y Darlo todo y no dar nada - no puede ni debe ser considerada la fuente de El maestro de Alejandro. Antonio Enríquez Gómez conocía Amar por razón de Estado de Tirso de Molina - citada en sus Academias morales de las musas - una obra muy próxima a ésta en cuanto contenido y estructura, y muy probablemente también conocía la traducción de Diez libros de la razón de Estado, que, indirectamente, pudo influir en su obra. Tanto las fuentes, como el género de la obra, han de ponerse en relación con el sentido, estudiado en $\S 3$, en donde explicamos que la finalidad de Antonio Enríquez Gómez no es crear una comedia estrictamente historial, sino que, a partir de las figuras regias y nobiliarias, pretende verter sus opiniones políticas de Política angélica y Luis dado de Dios a Luis y Ana Samuel dado de Dios a Elcana y Ana.

\section{Referencias bibliográficas}

Alfonso X el Sabio (2009), General Estoria, 10 v., coordinado por Pedro Sánchez-Prieto Borja, Madrid, Fundación José Antonio de Castro.

Arata, Stefano (1989), Miguel Sánchez il «Divino» e la nascita della «comedia nueva», Salamanca, Servicio de Publicaciones de la Universidad de Salamanca.

Bances Candamo, Francisco Antonio de (1970), Teatro de los teatros de los pasados y presentes siglos, edición de D. Moir, Londres, Tamesis Books.

CALDERÓN CALDERón, Manuel (2017), «Autoridad, poder y razón de Estado en el teatro de Antonio Enríquez Gómez», en Revista de literatura, 157, págs. 95-120.

Calderón de la Barca, Pedro de (2019), Darlo todo y no dar nada, Barcelona, Red Ediciones.

EnRíquez Gómez, Antonio (2019a), Política angélica, edición crítica, estudio y notas de Felice Gambin, Huelva, Servicio de Publicaciones de la Universidad de Huelva.

EnRíquez Gómez, Antonio (2019b), Comedias II. Volumen I: Engañar para reinar, El gran cardenal de España, don Gil de Albornoz, El primer rey del mundo, edición crítica y anotada del Instituto Almagro de Teatro clásico, dirigida por 
Rafael González Cañal y Almudena González García, Cuenca, Ediciones de la Universidad de Castilla-La Mancha.

EnRíluez Gómez, Antonio (2018), Comedias. Volumen I: A lo que obligan los celos, Celos no ofenden al sol, No hay contra el honor poder, edición crítica y anotada del Instituto Almagro de Teatro clásico, dirigida por Rafael González Cañal y Almudena González García, Cuenca, Ediciones de la Universidad de Castilla-La Mancha.

EnríQuez Gómez, Antonio (2015), Academias morales de las musas, 2 vols., edición crítica y anotada del Instituto Almagro de Teatro clásico, dirigida por Milagros Rodríguez Cáceres y Felipe B. Pedraza Jiménez, Cuenca, Ediciones de la Universidad de Castilla-La Mancha.

Florit Durán, Francisco de (2000), «El vergonzoso en palacio: arquetipo de un género)», en Ignacio Arellano Ayuso y Blanca Oteiza Pérez (eds.), Varia lección de Tirso de Molina (Actas del VIII Seminario del Centro para la Edición de Clásicos Españoles, Madrid, Casa de Velázquez, 5-6 de julio de 1999), Madrid-Pamplona, Instituto de Estudios Tirsianos, pp. 65-83.

García GonZÁlez, Almudena (2015), «Estudio de Amor con vista y cordura», en Antonio Enríquez Gómez: Academias morales de las musas. Tomo I, edición crítica y anotada del Instituto Almagro de Teatro clásico, dirigida por Milagros Rodríguez Cáceres y Felipe B. Pedraza Jiménez, Cuenca, Ediciones de la Universidad de Castilla-La Mancha, págs. 187-205.

Gómez Espelosín, Francisco Javier (2001), Historia de Grecia antigua, Madrid, Akal.

GonzÁlez CAÑal, Rafael (2017), «La figura del rey en el teatro de Enríquez Gómez», en Bulletin hispanique, 119, págs. 187-202.

González Cañal, Rafael (2015), «Estudio de A lo que obliga el honor», en Antonio Enríquez Gómez: Academias morales de las musas. Tomo I, edición crítica y anotada del Instituto Almagro de Teatro clásico, dirigida por Milagros Rodríguez Cáceres y Felipe B. Pedraza Jiménez, Cuenca, Ediciones de la Universidad de Castilla-La Mancha, págs. 131-152.

GutiérRez GiL, Alberto (2019), «Torres y castillos como espacios de prisión y aislamiento en el género palatino de Francisco de Rojas Zorrilla», en Diablotexto Digital, 5, págs. 5 - 25. 
Julio GimÉnez, Teresa (2018), «Prólogo a No hay contra el honor poder», en Antonio Enríquez Gómez: Comedias. Volumen I, edición crítica y anotada del Instituto Almagro de teatro clásico, dirigida por Rafael González Cañal Almudena García González, Cuenca, Ediciones de la Universidad de Castilla-La Mancha, págs. 277-296.

Lida de Malkiel, María Rosa (1957), «Alejandro en Jerusalén», en Romance Philology, 10, págs. 185-196.

Lievens, Anne-Marie (2020), «Lope y Pérez de Pineda: la materia histórica en Las grandezas de Alejandro», en Anuario de Lope de Vega, 20, págs. 404-444.

Lievens, Anne-Marie (2017), véase Vega, Lope de, Las grandezas de Alejandro.

Molina, Tirso de (2019), Amar por razón de Estado, edición de Francisco Sáez Raposo, Nueva York/Madrid, Instituto de Estudios Auriseculares (IDEA)/Instituto de Estudios Tirsianos (IET).

OlezA, Joan (1997), «La comedia y la tragedia palatinas: modalidades del arte nuevo», en Edad de Oro, 16, 1997, págs. 235-51.

Mejía, Pedro (2003), Silva de varia lección, edición de Isaías Lerner, Madrid, Castalia.

PARKER, Alexander (1976), «Aproximación al drama español del Siglo de Oro», en M. Durán y R. González Echeverría (eds.), Calderón y la crítica: historia y antología, vol. I, Madrid, Gredos, págs. 329-57.

Pejenaute Rubio, Francisco (1991), «El episodio del nudo gordiano en las sendas comedias de Calderón y Lope de Vega», en Excerpta Philologica: Revista de Filología Griega y Latina de la Universidad de Cádiz, 1, págs. 601-614.

Pejenaute Rubio, Francisco (1985), «Notas a ‘Las grandezas de Alejandro' de Lope de Vega», en Archivum: Revista de la Faculta de Filología, 34-35, págs. 165-182.

Pérez de Pineda, Juan (1588), Los treinta libros de la monarquía eclesiástica o historia universal del mundo, divididos en cinco tomos, Juan Fernández, Salamanca, 1588. 
Plinio Cecilio, Segundo Cayo (2002), Historia natural, edición y traducción de Josefa Cantó, Madrid, Cátedra.

SÁEz RAPoso, Francisco (2019), «Introducción» a Tirso de Molina: Amar por razón de Estado, edición de Francisco Sáez Raposo, Nueva York/Madrid, Instituto de Estudios Auriseculares (IDEA)/Instituto de Estudios Tirsianos (IET), págs. 13-69.

SerRALTA, Frédéric (1988), «El enredo y la comedia: deslinde preliminar», en Criticón, 42, págs. 125-37.

Textor, Ravisio (1699), Officina, Venecia, Michaelem Milochum.

Urzáiz Tortajada, Héctor (2002), Catálogo de autores teatrales del siglo XVII, Madrid, Fundación Universitaria Española.

VegA, Lope de (2017), Las grandezas de Alejandro, edición de Anne-Marie Lievens, en Florence d'Artois y Luigi Giuliani (coord.): Comedias de Lope de Vega. Parte XVI, volumen 2, Madrid, Gredos pp. 291-442.

VegA, Lope de (s.a.), La mayor hazaña de Alejandro, s. 1., s. i., BNE (ms. 15566).

Viveros, Germán (2005), Manifestaciones teatrales de Nueva España, México, UNAM / CONACYT.

WARDRopper, Bruce W., (1978), «La comedia española del Siglo de Oro», en E. Oison, Teoría de la comedia, Barcelona, Ariel, págs. 181-242.

Weber de Kurlat, Frida (1977), «Hacia una sistematización de los tipos de comedias de Lope de Vega», en M. Chevalier, F. López, J. Perez y N. Salomon (eds.), Actas del Quinto Congreso Internacional de Hispanistas (Bordeaux, 2- 8 de septiembre de 1974), vol. II, Bordeaux, Instituto de Estudios Ibéricos e Iberoamericanos, págs. 867-71.

Weber de Kurlat, Frida (1976), «Hacia una morfología de la comedia del Siglo de Oro», en Anuario de Letras, 14, págs. 101-38.

Weber de Kurlat, Frida (1975), «El perro del hortelano, comedia palatina», en Nueva Revista de Filología Hispánica, 24, págs. 339-63. 
Zugasti Zugasti, Miguel (2003), «Comedia palatina cómica y comedia palatina seria en el Siglo de Oro», en Eva Galar Irrure y Blanca Oteiza Pérez (coords.), El sustento de los discretos: la dramaturgia áulica de Tiros de Molina: Actas del Congreso internacional organizado por el GRISO, $4-6$ de junio de 2003, Monasterio de Poyo, Pamplona, Instituto de Estudios Tirsianos, págs. $159-185$. 


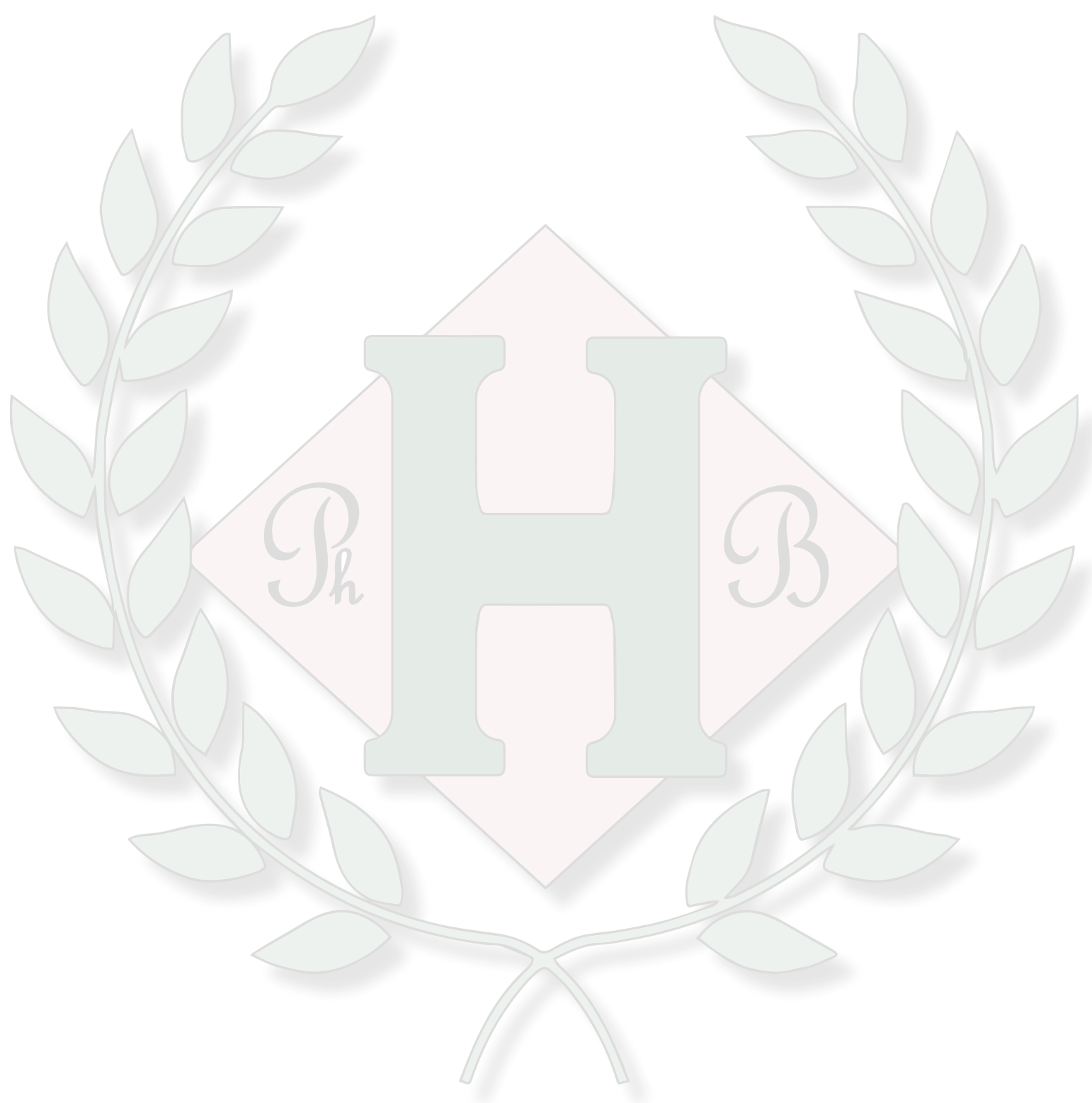

